\title{
A Comparative Study to Assess the Level of Anxiety among Primi Gravida Mothers Planned for Normal Vaginal Delivery and Caesarean Section in the Selected Hospital, Agartala, West Tripura
}

\author{
Ishita Nath \\ Assistant Professor, Manmohini Academic Institution, Berhampore, Murshidabad
}

\begin{abstract}
A comparative study was conducted among 100 primi gravida mothers (50 mothers in each group) from $\mathrm{MCH}$ clinic and IPD of IGM hospital, Agartala, West Tripura, who had planned for normal vaginal delivery and caesarean section. Research approach used was non experimental quantitative approach and research design was descriptive comparative design. Purposive sampling technique was used to draw the sample. Socio demographic data and modified Perinatal Anxiety Screening Scale were used to collect data from the samples through interview method. Analysis revealed that $52 \%$ of the primi gravida who had planned for caesarean section and $44 \%$ mothers who had planned for normal vaginal delivery had mild symptoms of anxiety. Mean anxiety score of the mothers who planned for caesarean section and normal vaginal delivery was 27.3 and 19.7 respectively, median 28.855 and 18.915 respectively and SD 7.0715 and 8.038 respectively. The mean difference was 7.6 and unpaired ' $t$ ' value was 5.0198, which was significant at $p<0.05$. Analysis of variance result showed that there was significant association between the level of anxiety of the primi gravida mothers who had planned for caesarean section with their selected socio demographic variable 'occupation of husband'. The calculated 'F' value was 3.33 at $p<0.05$. The researcher concluded that the primi gravida mothers who had planned for caesarean section had more anxiety than the mothers who had planned for normal vaginal delivery and the anxiety level of the mothers who had planned for caesarean section was dependent on selected demographic variable occupation of the husband.
\end{abstract}

Key words: Anxiety, primi gravida, normal vaginal delivery, caesarean section.

\section{INTRODUCTION}

Every woman feels that becoming a mother is the gift of God. Childbirth is universally celebrated event like a shining star in the hand at night. This occasion cherish each individual and the mother the most, at the same time the mother experience pain, fear, anxiety, stress and depression due to an unknown experience, outcome and the responsibilities as a mother to a little star who newly joined to the family, for the family and for the society.

Anxiety is a factor that comes associated with pain. It is a feeling of nervousness, apprehension, fear or worry, which can occur with or without cause. Mild anxiety is considered normal for women during labour and birth. However, excessive anxiety and fear increases catecholamine secretion, from it severity resulting in more pelvic pain. Anxiety is a multisystem response to a perceived threat or danger. It reflects a combination of biochemical changes in the body, the patient's personal history and memory, and the social situation.

Most women and healthcare providers view an undefined level of anxiety as common and acceptable in pregnancy. ${ }^{[1]}$ In 2015 WHO report showed that, worldwide about $10 \%$ of pregnant women and $13 \%$ of women who have just given 
birth, experience a mental disorder, primarily depression and anxiety. In developing countries this is even higher i.e. $15.6 \%$ in pregnancy and $19.8 \%$ after childbirth. ${ }^{[2]}$

$$
\text { According to a prospective }
$$

explorative survey done by

Madhavanprabhakaran KG., Dsouza M. and Nairy SK. in 2015 in Kerala, India, the highest prevalence $(22 \%)$ of severe degree of pregnancy-specific anxiety was reported during third trimester. Almost 99\% women at third trimester had moderate to severe degree of pregnancy-specific anxiety. ${ }^{[3]}$

\section{MATERIALS AND METHODS}

Research Approach: Non experimental quantitative approach

Research Design: Descriptive comparative design

Research Setting: Maternal and Child Health clinic and In-Patient Department of Indira Gandhi Memorial hospital, Agartala, West Tripura.

Sampling Technique: Purposive sampling technique

Sample Size: 100 primi gravida mothers (50 mothers who had planned for normal vaginal delivery and 50 mothers who had planned for caesarean section)

Description of the Tool: The tool used in the study consisted of 2 sections.

Section A: Socio demographic data, which was divided into 2 parts, Demographic proforma and Health related information. In Demographic proforma there was 10 questions and in Health related information there was 5 questions.

Section B: Modified Perinatal Anxiety Screening Scale, which consisted of 20 questions. Scoring instructions for Modified Perinatal Anxiety Screening Scale was:

For each item there were 4 options:

- Not at all: 0

- Sometimes: 1

- Often: 2
- Almost always: 3

If all 20 items were answered as 'almost always', the calculation would be like:

$3 \times 20=60$

Interpretation of scores for Modified Perinatal Anxiety Screening Scale was:

Asymptomatic: 0-15

Mild symptoms: 16-30

Moderate symptoms: $31-45$

Severe symptoms: 46-60

The tool was validated by 9 experts. The reliability of the tool was found to be 0.94 which was tested by test-retest method and was found highly reliable. The tool was translated into Bengali and also re-translated into English by experts to determine appropriateness.

Data Collection Method: Interview method

\section{Statistical Methods}

The data obtained from the subjects were tabulated and analyzed in terms of objectives of the study using descriptive (frequency, percentage) and inferential statistics (mean, median, mode, SD, unpaired $t$ test and ANOVA). $\mathrm{P}$ value $<0.05$ was considered as significant.

Results

The result revealed that $52 \%$ of the primi gravida who had planned for caesarean section and $44 \%$ of the primi gravida mothers who had planned for normal vaginal delivery were having mild symptoms. The mean anxiety score of the primi gravida mothers who had planned for caesarean section and normal vaginal delivery was found to be 27.3 and 19.7 respectively, median 28.855 and 18.915 respectively and SD was 7.0715 and 8.038 respectively. The mean difference was 7.6 and unpaired ' $\mathrm{t}$ ' value was 5.0198 (table value 1.98) which was found to be significant at $p<0.05$. Analysis of variance result showed that there was significant association between the level of anxiety of the primi gravida mothers who had planned for caesarean section with their selected socio demographic variable 'occupation of 
Ishita Nath. A comparative study to assess the level of anxiety among primi gravida mothers planned for normal vaginal delivery and caesarean section in the selected hospital, Agartala, West Tripura.

husband'. The calculated ' $F$ ' value was 3.33 and tabulated ' $F$ ' value was 3.23 at $p<0.05$.

Table 1: Frequency and percentage distribution on level of anxiety of the primi gravida mothers
\begin{tabular}{|l|c|c|c|c|}
\hline INTERPRETATION OF SCORES & \multicolumn{2}{c|}{ CAESAREAN SECTION } & NORMAL VAGINAL DELIVERY \\
\cline { 2 - 5 } & $\begin{array}{c}\text { FREQUENCY } \\
(\mathbf{f})\end{array}$ & $\begin{array}{c}\text { FREQUENCY } \\
(\boldsymbol{\%})\end{array}$ & $\begin{array}{c}\text { FREQUENCY } \\
(\mathbf{f})\end{array}$ & $\begin{array}{c}\text { FREQUENCY } \\
(\%)\end{array}$ \\
\hline Asymptomatic (0-15) & 5 & $10 \%$ & 20 & $40 \%$ \\
\hline Mild symptoms (16-30) & 26 & $52 \%$ & 22 & $44 \%$ \\
\hline Moderate symptoms (31-45) & 19 & $38 \%$ & 8 & $16 \%$ \\
\hline Severe symptoms (46-60) & 0 & $0 \%$ & 0 & $0 \%$ \\
\hline
\end{tabular}

Minimum possible score $=0$

Table 1 depicts that $10 \%$ of the primi gravida who had planned for caesarean section are asymptomatic (0-15) followed by $52 \%$ who are having mild symptoms (16-30) and remaining 38\% are having moderate symptoms (31-45). $40 \%$ of the primi gravida mothers who had planned for normal vaginal delivery are asymptomatic (0-15) followed by $44 \%$ who are having mild symptoms (16-30) and 16\% are having moderate symptoms (31-45).

Table 2 shows, the mean anxiety score of the mothers who had planned for caesarean section is 27.3 , median 28.855 and SD 7.0715. In case of the mothers who had planned for normal vaginal delivery the mean anxiety score is 19.7 , median 18.915 and SD 8.038. The mean difference is 7.6.

Table 2: Comparison of mean, median, SD, mean difference and ' $t$ ' value on level of anxiety among primi gravida mothers planned for normal vaginal delivery and caesarean section

\begin{tabular}{|l|c|c|c|c|c|}
\hline \multicolumn{1}{|c|}{ GROUP } & MEAN & MEDIAN & SD & MEAN DIFFERENCE & 't' VALUE \\
\hline Caesarean section & 27.3 & 28.855 & 7.0715 & & \multirow{2}{*}{$5.0198^{*}$} \\
\hline Normal vaginal delivery & 19.7 & 18.915 & 8.038 & 7.6 & \multirow{2}{*}{$*$} \\
\hline
\end{tabular}

\section{DISCUSSION}

The statistical findings of the study revealed that $10 \%$ of the primi gravida who had planned for caesarean section were asymptomatic followed by $52 \%$ who were having mild symptoms and remaining $38 \%$ were having moderate symptoms. $40 \%$ of the primi gravida mothers who had planned for normal vaginal delivery were asymptomatic followed by $44 \%$ who were having mild symptoms and $16 \%$ were having moderate symptoms.

The mean anxiety score of the primi gravida mothers who had planned for caesarean section was 27.3 , median 28.885 and SD was 7.0715. Among the primigravida mothers who had planned for normal vaginal delivery mean anxiety score was 19.7, median 18.915 and SD was 8.038. Mean difference was 7.6 and calculated ' $\mathrm{t}$ ' value was 5.0198 which was significant at $\mathrm{p}<0.05$.

There was significant association between the level of anxiety of the primi gravida mothers who had planned for caesarean section with their selected demographic variable 'occupation of husband' which was significant at the level of $\mathrm{p}<0.05$ but there was no significant association between the level of anxiety of the primi gravida mothers who had planned for normal vaginal delivery with their selected demographic variables.

According to an explorative study conducted by Raksha G., Anjali T. and Kirna T. in 2017 in Patiala, Punjab, revealed that $65 \%$ primi gravida mothers had moderate level of anxiety in normal vaginal delivery and $55 \%$ in caesarean section and $45 \%$ and $35 \%$ in each caesarean section and normal vaginal delivery had low anxiety respectively. The level of anxiety was found to be higher in case of caesarean section with a mean score of 24.85 , whereas the mean score in normal vaginal delivery was 20.35. Mean difference was 4.5. The calculated ' $\mathrm{P}$ ' value was 0.044 which was significant at $\mathrm{p}<0.05{ }^{[4]}$

According to a descriptive study conducted by Silwal M., Jacob V and Imran S. in 2015 in Mangalore, focused that there was significant association between level of anxiety and selected variables like number of pregnancies $\left(\mathrm{x}^{2}=15.333, \mathrm{p}<0.05\right)$, number 
of full-term delivery $\left(\mathrm{x}^{2}=14.338, \mathrm{p}<0.05\right)$, number of abortion $\left(\mathrm{x}^{2}=5.114, \mathrm{p}<0.05\right)$, number of live children $\left(x^{2}=5.104, p<0.05\right)$, planned pregnancy $\left(\mathrm{x}^{2}=6.823, \mathrm{p}<0.05\right)$, history of depression $\left(\mathrm{x}^{2}=17.773, \mathrm{p}<0.05\right)$, history of counseling $\left(\mathrm{x}^{2}=5.393, \mathrm{p}<0.05\right)$ and present physical health of the sample $\left(\mathrm{x}^{2}=6.734, \mathrm{p}<0.05\right) .{ }^{[5]}$

\section{CONCLUSION}

The present study showed that the primi gravida mothers who had planned for caesarean section had more anxiety than the primi gravida mothers who had planned for normal vaginal delivery and 'Occupation of husband' was an independent variable which indicated that the anxiety level of the primi gravida mothers who had planned for caesarean section was dependent on the occupation of the husband as maximum were private employee.

\section{Acknowledgement: None}

\section{Conflict of Interest: None}

\section{Source of Funding: None}

Ethical Approval: Ethical approval was taken from the concerned authorities of the hospital and informed consent was obtained from the samples.

\section{REFERENCES}

1. Cooper AM, Fraser MD. Myles Textbook for Midwives. $14^{\text {th }}$ edn. New York:
Churchill Livingstone publishers; 2003. p. 234-227.

2. WHO. Maternal and child mental health. [Internet]. 2015. Available from: https://who.int/mental_health/maternal-child

3. Girija Kalayil Madhavanprabhakaran, Melba Dsouza and Karkada Subrahmanya Nairy. Prevalence of pregnancy anxiety anxiety and associated factors. International Journal of Africa Nursing Sciences [Internet]. 2015; 3: 1-7. Available from https://doi.org/10.1016/j.ijans.2015.06.002

4. Raksha G, Anjali $\mathrm{T}$ and Kirna T. An Exploratory Study to Assess the Factors Causing Anxiety among Primigravida Planned for Normal Vaginal Delivery and Caesarean Section Admitted at Mata Kaushalya Hospital, Patiala, Punjab. Maternal and Pediatric Nutrition Journal. 2017; 3 (1): 1-8.

5. Muna Silwal, Jacob V and Imran S. A descriptive study to assess the level of anxiety and depression among antenatal mothers in a selected hospital, Mangalore, with a view to develop an information booklet. International Journal of Recent Scientific Research. August 2015; 6 (8): 5699-5703.

How to cite this article: Nath I. A comparative study to assess the level of anxiety among primi gravida mothers planned for normal vaginal delivery and caesarean section in the selected hospital, Agartala, West Tripura. International Journal of Science \& Healthcare Research. 2021; 6(2): 58-61. DOI: https://doi.org/ 10.52403/ijshr.20210412 